\title{
KELIMPAHAN DAN KOMPOSISI FITOPLANKTON DI DAS BATANGHARI BAGIAN HILIR, PROPINSI JAMBI
}

\author{
Samuel "), Zahri Nasution ${ }^{*}$ ) dan Akrimi*)
}

\begin{abstract}
ABSTRAK
Suatu pengamatan terhadap fitoplankton telah dilakukan di DAS Batanghari bagian hilir. Tujuan pengamatan adalah untuk mengetahui komposisi dan kelimpahan fitoplankton dihubungkan dengan masalah pencemaran di berbagai habitat baik pada keadaan air surut maupun pasang. Pengambilan contoh plankton menggunakan plankton net No.25 di 5 stasion pengamatan pada keadaan air rendah/surut (November 1994) dan pada keadaan air tinggi/pasang (Januari 1995).

Dari hasil pengamatan ditemukan 25 genera fitoplankton dari 4 famili dengan kelimpahan tertinggi terjadi pada stasion 1 pada saat air rendah. Indeks keragaman $\left(\mathbf{H}^{\prime}\right)$ dan indeks keseragaman (E) tidak menunjukkan perbedaan yang begitu besar antara stasion satu dengan stasion yang lainnya.
\end{abstract}

ABSTRACT: The Abundance and Composition of Phytoplanktons in the Lower Batanghari River basins, Jambi, by Samuel, Zabri Nasution and Akrimi.

An observation of the abundance and composition of phytoplanktons was conducted in the lower Batanghari river basin. The purpose of this research was to evaluate the abundance and composition of phytoplanktons at some habitats, not only in lower water level condition (November 1994) but also in upper water level condition (January 1995). Phytoplanktons were sampled by using plankton net No.25 at five representative stations.

Results showed that 25 genera of phytoplanktons of 4 families were identified. At station 1 in November 1994, the individual number of phytoplanktons were more plentiful than other stations. Based on the mathematic calculations of diversity index $\left(H^{\prime}\right)$ and uniformity index $(E)$ it shown that the values of both indices were not significantly difference among stations, even in November 1994 or January 1995.

KEYWORDS: Pbytoplankton, river basin, abundance

\section{PENDAHULUAN}

Perkembangan industri di Indonesia dewasa ini telah mendudukkan wilayah bagian hilir dari suatu Daerah Aliran Sungai (DAS) dalam posisi yang penting. Pusat-pusat industri, pemukiman dan aktivitas lain yang berhubungan dengan lingkungan perairan kini banyak dibangun di wilayah ini. Dampak negatif yang akan timbul dapat berupa menurunnya populasi biota air dan rusaknya beberapa habitat penting seperti daerah pemijahan (spawning ground) dan daerah asuhan ikan (nursery ground).

DAS Batanghari bagian hilir merupakan salah satu bagian DAS Batanghari yang meliputi Kotamadya Jambi, Kabupaten Batanghari dan Kabupaten

*) Peneliti pada Loka Penelitian Perikanan Air Tawar Palembang 
Tanjung Jabung. Industri di wilayah ini cukup banyak, di samping itu, aktivitas penangkapan dan kegiatan budidaya ikan untuk memenuhi kebutuhan masyarakat akan ikan air tawar sebagian besar dilakukan di wilayah ini (Team Survei IPB, 1986).

Banyaknya industri ditambah dengan aktivitas penangkapan dan budidaya ikan akan berpengaruh terhadap kelestarian sumber daya perairan sekitarnya. Salah satu cara untuk memonitor hal tersebut adalah dengan melihat kelimpahan dan komposisi fitoplankton pada perairan yang diamati. Hal ini disebabkan karena fitoplankton merupakan produsen pertama di semua perairan alami serta terlibat langsung dalam rantai makanan ke produksi ikan (Odum, 1971; Kaswadjie, 1976; Needham and Needham, 1963).

Penelitian ini bertujuan untuk mengetahui perbedaan komposisi dan kelimpahan fitoplankton yang ada di berbagai habitat (lebak, sungai dan danau) yang terdapat di bagian hilir DAS Batanghari pada keadaan air surut dan pasang. Informasi yang diperoleh dari penelitian ini diharapkan dapat menjadi bahan pertimbangan bagi pemegang kebijaksanaan dalam mengambil keputusan di samping sebagai data dasar bagi penelitian di masa mendatang.

\section{BAHAN DAN METODE}

Pengambilan contoh fitoplankton dilakukan sebanyak dua kali yaitu pada keadaan air surut/rendah (November 1994) dan pada keadaan air pasang/tinggi (Januari 1995). Pada saat air pasang, arus air Sungai Batanghari bagian hilir lebih lambat dibandingkan pada waktu air surut dan temperatur rata rata lebih rendah. Penelitian dilakukan menggunakan pendekatan survei dengan cara mengambil contoh fitoplankton pada berbagai stasion penelitian yang representatif di DAS Batanghari bagian hilir. Stasion pengambilan contoh ditentukan secara purposive (sengaja) dengan kriteria dapat mewakili dan menggambarkan DAS Batanghari bagian hilir (Figure 1). Stasion tersebut adalah sebagai berikut: (1) Desa Sogo, merupakan perairan sungai yang dekat dengan perairan estuari; (2) Desa Rukam, merupakan perairan sungai yang tidak dipengaruhi oleh perairan estuari; (3) Dusun Mudo, perairan sungai yang di kiri kanannya banyak terdapat industri antara lain: industri karet, minyak kelapa sawit dan industri plywood (kayu lapis); (4) Danau Arang Arang, merupakan perairan lebak dan rawang yang banyak terdapat aktivitas penangkapan ikan; dan (5) Danau Mudung, merupakan perairan danau (oxbow lake) yang terletak di Kotamadya Jambi dan telah dikelilingi oleh banyak pemukiman penduduk.

Pengumpulan fitoplankton dilakukan dengan cara menyaring air contoh sebanyak 50 liter kedalam jaring plankton No.25 untuk dikonsentrasikan ke dalam botol vial menjadi $25 \mathrm{ml}$. Contoh fitoplankton yang telah terkonsentrasi dalam botol vial diberi larutan pengawet "lugol" sebanyak 5 tetes dan untuk selanjutnya diperiksa di laboratorium untuk diidentifikasi jenis dan diukur kelimpahannya. Dalam identifikasi jenis fitoplankton, digunakan buku 
petunjuk APHA (1980); Needham and Needham (1963); dan Sachlan (1972). Kelimpahan fitoplankton diukur berdasarkan metoda Sedwick Rafter (Welch, 1962; Edmonson, 1971) yaitu:

$$
N=\frac{n s \times v a}{v S \times v c}
$$

$N=$ jumlah individu fitoplankton per liter air contoh

ns = jumlah individu fitoplankton pada Sedwick Rafter

va $=$ volume air terkonsentrasi dalam botol vial $(25 \mathrm{cc})$

vs = volume air dalam preparat Sedwick Rafter (1 cc)

$v c=$ volume air contoh yang disaring (50 liter)

Untuk mengukur indeks keragaman $\left(\mathrm{H}^{\prime}\right)$ dan indeks keseragaman (E) digunakan rumus yang dikemukakan oleh Odum (1971) yaitu:

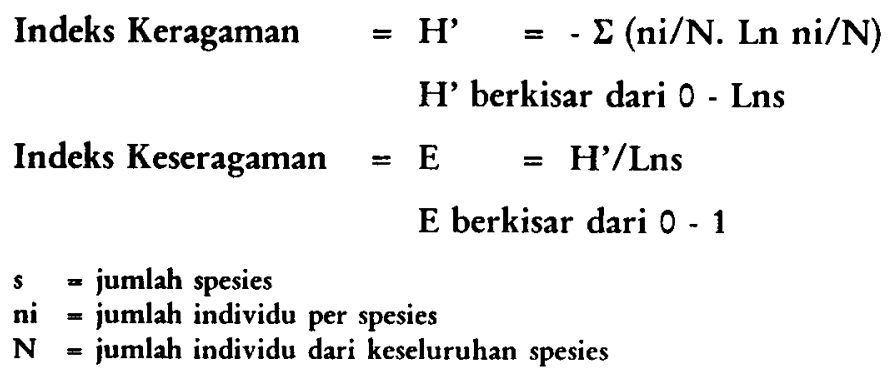

Dari kedua rumus tersebut ( $H^{\prime}$ dan E) memberikan gambaran bahwa semakin tinggi nilai $H^{\prime}$ ' maka keragaman spesies perairan yang diteliti semakin tinggi. Sedangkan untuk nilai indeks keseragaman (E), semakin tinggi nilai $E$ akan semakin tinggi pula keseragaman populasi, di mana jumlah individu setiap spesies dapat dikatakan sama. Untuk data pendukung, dilakukan pula pengukuran kualitas air terdiri dari suhu, kecerahan, $\mathrm{pH}$, oksigen terlarut, karbon dioksida bebas, alkalinitas, phospat, nitrat, nitrit dan ammoniak.

\section{HASIL DAN PEMBAHASAN}

\section{Hasil Pengamatan}

Fitoplankton yang ditemukan di DAS Batanghari bagian hilir berjumlah 25 genera dari 4 famili yaitu Chlorophyceae (8 genera), Cyanophyceae (5 genera), Desmidiaceae ( 3 genera) dan Bacillariophyceae ( 9 genera). Jumlah spesies dan populasi fitoplankton pada keadaan air rendah (November 1994) berkisar antara 17-20 jenis dengan jumlah 256-784 individu/liter, sedangkan pada keadaan air tinggi (Januari 1995) berkisar antara 11-20 jenis berjumlah 122-444 individu/liter. Populasi tertinggi ditemukan pada stasion (1) bulan November 1994 yaitu sekitar 784 individu/liter dan populasi terendah ditemukan pada stasion (2) bulan Januari 1995 berjumlah sekitar 122 individu/liter (Table 1). 
Komposisi jumlah spesies, individu, indeks keragaman $\left(\mathrm{H}^{\prime}\right)$ dan indeks keseragaman tertera pada Table 2.

Table 1. Abundance and composition of phytoplanktons in the lower Batangbari river basins in November 1994 and January 1995

\begin{tabular}{|c|c|c|c|c|c|c|c|c|c|c|c|}
\hline \multirow{3}{*}{ No. } & \multirow{3}{*}{ Species } & \multicolumn{10}{|c|}{ Abundance of pbytoplankenon (ind. 7 ) } \\
\hline & & \multicolumn{4}{|c|}{$\begin{array}{c}\text { November, } 1994 \\
\text { (dry season) }\end{array}$} & \multicolumn{6}{|c|}{$\begin{array}{l}\text { January, } 1995 \\
\text { (rainy season) }\end{array}$} \\
\hline & & 1 & 2 & 3 & 4 & 5 & 1 & 2 & 3 & 4 & 5 \\
\hline$I$ & CHLOROPHYCEAE : & & & & & & & & & & \\
\hline 1 & Pediastrum & 40 & 32 & 12 & 20 & 8 & 20 & - & - & - & - \\
\hline 2 & Dictyosphaerium & 52 & - & 20 & 20 & 4 & 34 & - & - & - & $\cdot$ \\
\hline 3 & Ankistrodesmus & 16 & 16 & 12 & 20 & 12 & 24 & - & - & 12 & 8 \\
\hline 4 & Richterelia & 24 & 24 & 8 & 8 & 16 & 20 & $\cdot$ & - & 36 & 8 \\
\hline 5 & Scenedesmus & 20 & 28 & 40 & 24 & 8 & 20 & - & - & 12 & 16 \\
\hline 6 & Spirogyra & $\cdot$ & 20 & 44 & 16 & 16 & - & - & - & 32 & - \\
\hline 7 & Mougeotia & 24 & 32 & - & 8 & - & 24 & 16 & 12 & 20 & 20 \\
\hline 8 & Ulotbrix & 28 & 12 & 8 & 8 & 8 & 16 & $\cdot$ & - & 12 & 28 \\
\hline$I I$ & CYANOPHYCEAE : & & & & & & & & & & \\
\hline 9 & Phormidium & - & - & 8 & - & - & - & $\cdot$ & $\cdot$ & $\cdot$ & - \\
\hline 10 & Anabaena & 44 & 8 & 28 & 24 & 24 & 24 & $\cdot$ & - & 16 & 20 \\
\hline 11 & Nostoc & - & - & 20 & 8 & 28 & 22 & - & - & 20 & - \\
\hline 12 & Oscillatoria & 104 & 32 & 20 & 8 & 16 & 24 & 8 & - & 8 & - \\
\hline 13 & Merismopedia & 44 & - & 16 & 4 & $\cdot$ & - & $\cdot$ & 8 & - & 24 \\
\hline$I I I$ & DESMIDLACEAE : & & & & & & & & & & \\
\hline 14 & Closterium & 64 & - & - & $\cdot$ & 12 & 28 & - & 12 & 32 & 32 \\
\hline 15 & Desmidium & 28 & 20 & - & 8 & 16 & 30 & - & 16 & - & - \\
\hline 16 & Micrasterias & - & 28 & 8 & 12 & 8 & 20 & 14 & 20 & - & - \\
\hline$I V$ & BACILLARIOPHYCEAE : & & & & & & & & & & \\
\hline 17 & Stephanodiscus & 88 & 36 & 24 & $\cdot$ & $\cdot$ & 24 & 6 & 8 & 18 & 8 \\
\hline 18 & Cyclotella & 32 & 48 & - & 8 & $\cdot$ & 26 & 10 & 8 & - & - \\
\hline 19 & Diatoma & 28 & 44 & 32 & 8 & 20 & 28 & 20 & 16 & 32 & 24 \\
\hline 20 & Fragillaria & 40 & 16 & - & - & - & - & 8 & 14 & 64 & - \\
\hline 21 & Nitzschia & 16 & 32 & 48 & 28 & 48 & 16 & 12 & 44 & 24 & 56 \\
\hline 22 & Synedra & 40 & $\cdot$ & 8 & 16 & 40 & 8 & 12 & 12 & 16 & 24 \\
\hline 23 & Navicula & 32 & 9 & 9 & 8 & 24 & 16 & 8 & 20 & 14 & 20 \\
\hline 24 & Tabellaria & 20 & - & 4 & - & - & $\cdot$ & 8 & 8 & 44 & - \\
\hline 25 & Asterionella & - & - & 24 & - & - & 20 & - & - & - & 8 \\
\hline 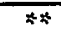 & Number of species & 20 & 17 & 20 & 19 & 17 & 20 & 11 & 13 & 17 & 14 \\
\hline$*$ & Number of Individual & 784 & 436 & 392 & 256 & 308 & 444 & 122 & 196 & 412 & 296 \\
\hline
\end{tabular}

Legend: 1. Sogo Village; 2. Rukam Village; 3. Mudo Village;

4. Arang-Arang Lake; 5. Mudung Lake

Dari Table 2, nilai indeks keragaman fitoplankton berkisar antara 2,34 sampai 2,96 (November 1994) dan antara 2,65 sampai 2,85 (Januari 1995). Nilai indeks keragaman terendah ditemukan pada stasion (2) bulan Januari 1995 
dengan nilai 2,34 dan nilai ini juga diikuti oleh jumlah spesies yang kecil yaitu 11 spesies (jenis) dan indeks keseragaman yang tinggi yaitu 0,97. Nilai indeks keragaman tertinggi dijumpai pada stasion (1) bulan Januari 1995 sebesar 2,96 yang ternyata diikuti pula oleh jumlah jenis yang tinggi yaitu 20 jenis dengan indeks keseragaman (E) sebesar 0,98.

Table 2. Number of species, individual, diversity index ( $\left.H^{\prime}\right)$ and uniformity index (E) of phytoplanktons in the lower Batanghari river basin, Jambi

\begin{tabular}{lccccc}
\hline \hline $\begin{array}{c}\text { Season and Parameter of } \\
\text { Observation }\end{array}$ & \multicolumn{5}{c}{ Station of Observation } \\
\cline { 2 - 6 } & 1 & 2 & 3 & 4 & 5 \\
\hline * November 1994: & & & & & \\
1. Number of species & 20 & 17 & 20 & 19 & 17 \\
2. Number of individual & 784 & 436 & 392 & 256 & 308 \\
3. Diversity Index & 2.85 & 2.73 & 2.79 & 2.81 & 2,65 \\
4. Uniformly Index & 0.95 & 0.96 & 0.93 & 0.95 & 0,94 \\
\hline$*$ January 1995: & & & & & \\
1. Number of species & 20 & 11 & 13 & 17 & 14 \\
2. Number of individual & 444 & 122 & 196 & 412 & 296 \\
3. Diversity index & 2.96 & 2.34 & 2.42 & 2.68 & 2,48 \\
4. Uniformly index & 0.98 & 0.97 & 0.94 & 0.95 & 0,94 \\
\hline \hline
\end{tabular}

\section{Pembahasan}

Stasion pengamatan 1 (Desa Sogo) merupakan perairan sungai Batanghari yang masih dipengaruhi oleh perairan estuari. Jenis fitoplankton seperti Oscillatoria, Cyclotella dan Stephanodiscus banyak ditemukan di daerah seperti ini dan biasanya selalu dominan dibandingkan dengan jenis fitoplankton yang lain (Kaswadjie, 1976; Mustikawati, 1982). Tingginya populasi fitoplankton pada keadaan air rendah/surut menurut Kardio dan Suwignyo (1980) karena kekeruhan air dan kecepatan arus pada saat musim kemarau lebih kecil dibandingkan pada musim hujan (keadaan air tinggi) sehingga pertumbuhan fitoplankton meningkat.

Stasion 2 (Desa Rukam) merupakan perairan sungai yang belum banyak dipengaruhi oleh aktivitas kegiatan manusia dan juga belum banyak industri. Jumlah jenis dari famili Bacillariophyceae pada keadaan air tinggi adalah dominan (8 genera) dan pada keadaan air rendah jenis dari famili Chlorophyceae dan Bacillariophyceae yang dominan masing-masing 7 dan 6 jenis. Di samping itu, jenis fitoplankton dari famili Bacillariophyceae banyak juga terdapat di stasion 3, 4 dan 5 (Table 1). Fitoplankton dari famili Bacillariophyceae adalah salah satu kelompok algae yang secara kualitatif maupun kuantitatif banyak terdapat di berbagai perairan tipe sungai, baik sebagai plankton maupun sebagai perifiton. Goldman and Horne (1983) mengatakan 
bahwa produktivitas primer pada perairan mengalir sebagian besar dihasilkan oleh fitoplankton dari famili Bacillariophyceae (ganggang kersik). Fitoplankton jenis Nitzschia yang terlihat dominan di stasion 3 dan 5, menurut Watanabe (1977) dalam Usman (1989) merupakan fitoplankton yang tergolong representatif dan toleran pada perairan tercemar bahan organik, yakni lebih berdaya hidup pada perairan yang telah mengalami pencemaran organik.

Dari nilai indeks keragaman dan indeks keseragaman, Odum (1971) dan Krebs (1985) mengatakan bahwa fitoplankton dengan jumlah jenis dan individu terkecil akan didapatkan nilai indeks keragaman terkecil pula sebagaimana tertera pada Table 2. Namun untuk nilai indeks keseragaman (E) tidak menunjukkan pola yang sama. Nilai E pada keadaan air rendah berkisar dari 0,93 sampai 0,96 dan pada keadaan air tinggi 0,94 sampai 0,98. Hal ini menunjukkan bahwa jumlah individu dari setiap jenis fitoplankton per stasion pengamatan dapat dikatakan hampir seragam dan tidak didapatkan adanya dominasi spesies.

Dilihat kemungkinan dari kegiatan pertanian pada DAS Batanghari bagian hilir, maka bahan penyubur yang berasal dari limbah pertanian di Desa ArangArang (stasion 4), areal industri dan perkebunan (stasion 3) dan juga di dekat perairan estuari (stasion 1) memberikan gambaran akan tingginya kandungan fosfat pada ketiga stasion tersebut (Table 3).

Table 3. Water quality of the lower Batanghari river basins at 5 research stations

\begin{tabular}{|c|c|c|c|c|c|c|c|c|c|c|}
\hline $\begin{array}{c}\text { Season } \& \text { Station of } \\
\text { Observation }\end{array}$ & $\boldsymbol{T}$ & $\boldsymbol{K}$ & pH & $\mathrm{O}_{2}$ & $\mathrm{CO}_{2}$ & Alk & $\mathrm{PO}_{4}$ & $\mathrm{NO}_{3}$ & $\mathrm{NO}_{2}$ & $\mathrm{NH}_{3}$ \\
\hline \multicolumn{11}{|l|}{ November 1994: } \\
\hline Station 1 & 28 & 55 & 6.5 & 7.35 & 9.90 & 119 & 0.12 & 0.51 & 0.24 & 0.65 \\
\hline Station 2 & 29 & 65 & 7.5 & 9.08 & 3.30 & 120 & 0.19 & 0.51 & 0.27 & 0.55 \\
\hline Station 3 & 29 & 60 & 6.5 & 7.08 & 6.60 & 108 & 0.13 & 0.48 & 0.33 & 0.80 \\
\hline Station 4 & 29 & 50 & 6.0 & 6.88 & 8.56 & 105 & 0.15 & 0.35 & 0.18 & 0.65 \\
\hline Station 5 & 30 & 75 & 7.0 & 8.79 & 6.60 & 200 & 0.15 & 0.57 & 0.37 & 0.95 \\
\hline \multicolumn{11}{|l|}{ January 1995: } \\
\hline Station 1 & 25 & 45 & 7.0 & 7.50 & 6.50 & 128 & 0.14 & 0.45 & 0.21 & 0.50 \\
\hline Station 2 & 26 & 40 & 6.5 & 7.08 & 8.56 & 115 & 0.15 & 0.47 & 0.22 & 0.45 \\
\hline Station 3 & 26 & 40 & 6.5 & 7.00 & 6.60 & 120 & 0.14 & 0.35 & 0.30 & 0.75 \\
\hline Station 4 & 25 & 35 & 7.0 & 7.48 & 4.29 & 140 & 0.15 & 0.44 & 0.20 & 0.40 \\
\hline Station 5 & 27 & 40 & 7.5 & 8.29 & 4.95 & 155 & 0.15 & 0.48 & 0.35 & 0.80 \\
\hline
\end{tabular}

Legend: $\quad T=$ Temperature $\rho C), K=$ Transparancy $(\mathrm{cm}), \mathrm{O}_{2}=$ Oxygen $(p p m)$, $\mathrm{CO}_{2}=$ Carbondioxida $(p p m)$, Alk = Alkalinity $(p p m), \mathrm{CaCO}_{3}$ (eq.), $\mathrm{PO}_{4}=$ Phosphate $(\mathrm{mg} / \mathrm{l}), \mathrm{NO}_{3}=$ Nitrate $(\mathrm{mg} / \mathrm{l}), \mathrm{NO}_{2}=$ nitrite $(\mathrm{mg} / \mathrm{l})$, dan $\mathrm{NH}_{3}=$ Ammonia $(\mathrm{mg} / \mathrm{l})$.

Menurut batasan yang ideal sebagaimana dikemukakan oleh Wardoyo (1980), kandungan fosfat terlarut di perairan alami biasanya tidak lebih dari 
$0,01 \mathrm{ppm}$. Namun hasil analisa menunjukkan kandungan fosfat berkisar antara 0,12 sampai $0,19 \mathrm{mg} / \mathrm{l}$ (November 1994) dan antara 0,14 sampai 0,15 (Januari 1995). Dengan kandungan fosfat sebesar itu sudah dapat menyebabkan penyuburan perairan dan sewaktu-waktu akan diikuti oleh adanya blooming fitoplankton di perairan setempat.

Fitoplankton yang blooming bila tidak segera dimanfaatkan akan mati dan mengalami perombakan serta penguraian oleh bakteri. Selanjutnya menimbulkan masalah bagi kehidupan organisme air lainnya seperti ikan dan udang. Adanya industri di pinggiran sungai dan juga pemukiman penduduk yang padat seperti di stasion 3 dan 5 perlu mendapatkan perhatian yang khusus. Aktivitas kehidupan yang sedang berlangsung ditempat tersebut potensial menimbulkan masalah di perairan setempat sehingga kemungkinan berbagai akibat yang timbul seperti menurunnya populasi ikan dan biota air lainnya perlu dipikirkan. Salah satu upaya untuk mempertahankan daya guna perairan adalah dengan selalu memonitor perkembangan sifat-sifat kimia, fisika dan biologi perairan tersebut.

\section{KESIMPUI.AN}

Dari hasil penelitian dapat disimpulkan sebagai berikut:

1. Ditemukan 25 jenis fitoplankton dari 4 famili yaitu Chlorophyceae (8 spesies), Cyanophyceae (5 spesies), Desmidiaceae (3 spesies) dan Bacillariophyceae ( 9 jenis).

2. Jumlah spesies fitoplankton pada keadaan air rendah berkisar antara 17 sampai 20 genera dan pada keadaan air tinggi berkisar antara 11 sampai 20 genera. Kelimpahan individu per liter umumnya lebih tinggi pada keadaan air rendah yaitu berkisar antara 256 sampai 784 individu/liter sedangkan pada keadaan air tinggi hanya berkisar antara 122 sampai 444 individu/liter.

3. Nilai indeks keragaman fitoplankton pada keadaan air rendah berkisar antara 2,65 sampai 2,85 dan pada keadaan air tinggi antara 2,34 sampai 2,96. Nilai keragaman tersebut berhubungan erat dengan jumlah jenis dan jumlah individu fitoplankton masing-masing stasion pengamatan.

4. Nilai indeks keseragaman fitoplankton tidak menunjukkan perbedaan yang nyata antara stasion yang satu dengan lainnya, baik pada keadaan air tinggi maupun pada keadaan air rendah.

5. Kandungan fosfat pada 5 stasion sudah lebih tinggi dari keadaan biasa, yaitu 0,12-0,19 mg/l pada November 1994 dan 0,14-0,50 mg/1 pada Januari 1995. Dengan kandungan fosfat setinggi itu sudah perlu diwaspadai terjadinya blooming. 


\section{DAFTAR PUSTAKA}

APHA. 1980. Standard Methods for the Examination of water and wastewater, 15th Edition. APHA Inc., New York. 1134 p.

Edmonson, G.G. 1971. A Manual and Methods for assessment of secondary productivity in freshwater. IBP. Handbook. Blackwell Sci. Publ. Oxford. 209 p.

Goldman, C.R. and A.J. Horne. 1983. Limnology. Int. Student Ed. McGrawHill International Book Co. Tokyo. 464 p.

Kardio, P. dan P. Suwignyo. 1980. Studi Drainage Dengkeng Basin berupa penyelidikan biologi perairan. Proyek Kerja Sama Antara BIOTROP dan P.U Kali Brantas, BIOTROP, Bogor. 32 p.

Kaswadjie, R.F. 1976. Studi Pendahuluan tentang Penyebaran dan Kelimpahan Fitoplankton di Delta Upang, Sumatera Selatan. Thesis pada Fakultas Perikanan IPB, Bogor. 110 p.

Krebs, J.K. 1985. Ecology The Experimental Analysis of Distribution and Abundance. Third Edition. Harper and Row Publisher, New York. 800 p.

Mustikawati, R. 1982. Kelimpahan dan Komposisi Fitoplankton di Perairan Cilacap. Karya Ilmiah pada Fakultas Perikanan IPB, Bogor. 107 p.

Needham, J.G. and D.R. Needham. 1963. A guide to the study of freshwater biology, 15th Edition. Holden Day Inc., San Fransisco. 108 p.

Odum, E.P. 1971. Fundamental of Ecology. Third Edition. W.B. Saunders Company, Toronto. $574 \mathrm{p}$.

Sachlan, M. 1972. Planktonologi. Correspondence Course Centre, Jakarta. 103p

Team Survei IPB. 1986. Survei jenis ikan perairan umum yang ekonomis penting dalam rangka pengembangan budidaya ikan di Propinsi Jambi. Fakultas Perikanan IPB, Bogor. 44 p.

Usman, R. 1989. Distribusi dan Kelimpahan Diatom Epilitik di Sungai Batang Hari, Kotamadya Padang. Berkala Perikanan Trubuk. Himpunan Alumni Fakultas Perikanan Riau. XIV (43): 35-44.

Wardoyo, S.T.H. 1980. Kriteria kualitas air untuk keperluan pertanian dan perikanan. Training Analisa Dampak Lingkungan, PUSDI-PSL, IPB, Bogor. 40 p.

Welch, P.S. 1962. Limnological Methods. Mc.Graw-Hill Book Company Ltd., New York. 381 p. 


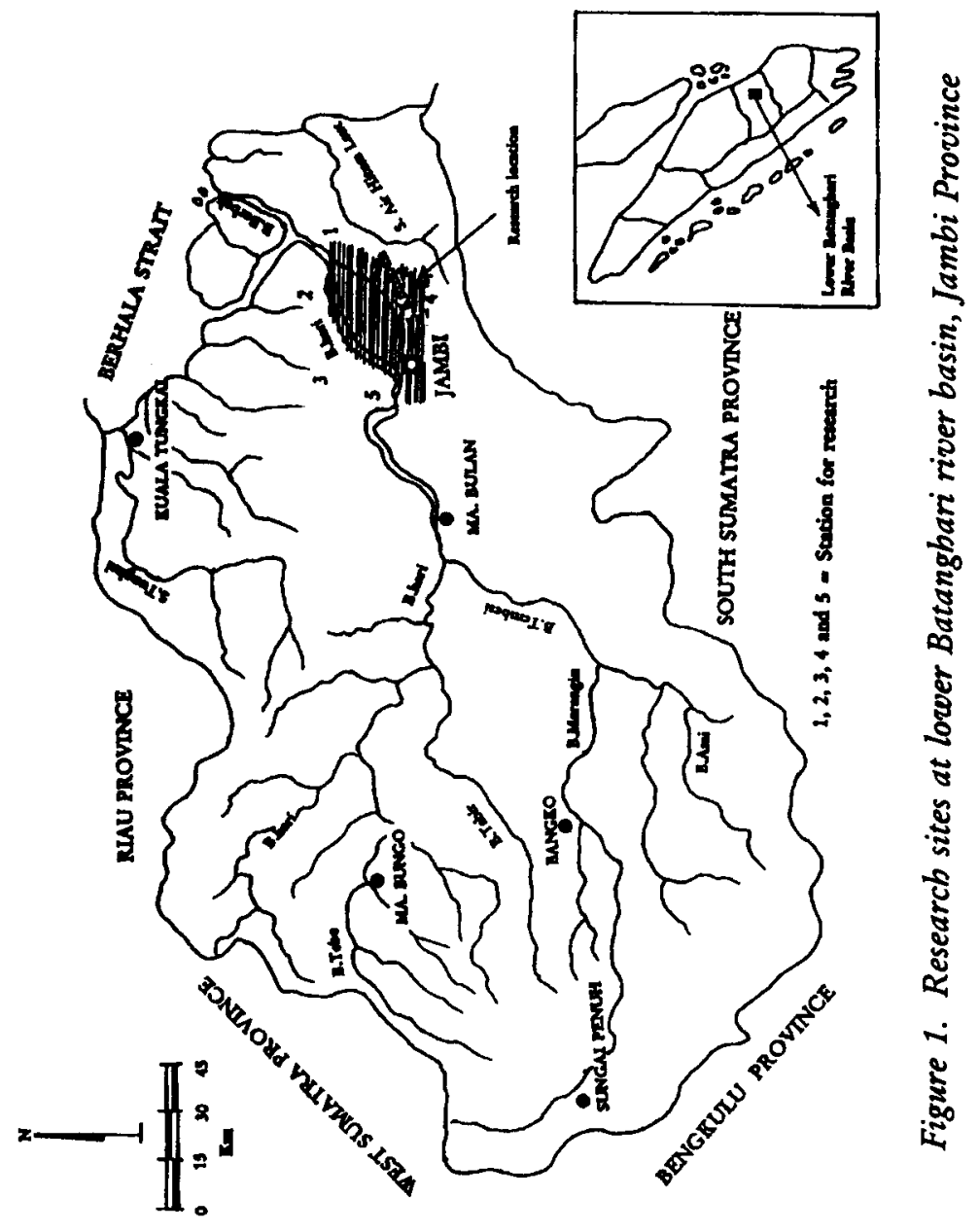

